\title{
An Energy-Adaptive MPPT Power Management Unit for Micro-Power Vibration Energy Harvesting
}

\author{
Jun Yi, Feng Su, Yat-Hei Lam, Wing-Hung Ki and Chi-Ying Tsui \\ Integrated Power Electronics Laboratory \\ Department of Electronic and Computer Engineering \\ The Hong Kong University of Science and Technology \\ Clear Water Bay, Hong Kong SAR, China \\ Fax: (852) 2358-1485; Email: \{eeyi, sufeng, hylas, eeki, eetsui\}@ece.ust.hk
}

\begin{abstract}
A batteryless power management unit (PMU) that manages harvested low-level vibration energy from a piezoelectric device for a wireless sensor node is presented. An energy-adaptive maximum power point tracking (EA-MPPT) scheme is proposed that allows the PMU to activate different operation modes according to the available power level. The harvested energy is processed by an ac-de voltage doubler followed by on-chip charge pumps with variable up/down conversion ratios for higher efficiency. Interleaving technique is employed for the high-power output to reduce both current and voltage ripples. The PMU is designed using a $0.35 \mu \mathrm{m}$ CMOS process, and simulation results are presented to demonstrate its functions.
\end{abstract}

\section{INTRODUCTION}

Energy harvested from the environment could replace or extend the lifetime of bulky batteries in a wireless sensor network, and vibration is a promising source of energy. For piezoelectric materials at a given vibration status (magnitude and frequency), there exists an optimum output voltage at which maximum output power can be extracted [1]. An ultralow-power maximum power point tracking (MPPT) scheme in a time-varying environment was discussed in [2] that tracked and held the maximum power point periodically using a very small duty cycle, and consumes only a fraction of the power required by prior MPPT schemes. All functional blocks are activated or shut down together. However, a sensor node consists of functional blocks with very different levels of power consumption. For example, signal processing may consume $20 \mu \mathrm{W}$ while RF power amplification and transmission may consume $1 \mathrm{~mW}$. The power management unit (PMU) should activate different blocks as the input power level changes. For example, at very low input power, the whole system may be duty-cycled; at medium input power the critical blocks work continuously while the rest are duty-cycled; and at high input power, all blocks are activated. To achieve energy-adaptive MPPT control, information on the absolute or relative amount of available power is needed. The problem is how to obtain and utilize this information without using power-demanding computational methods such as quantizing voltages and/or currents.

Prior research works focused on applications that consume power in the order of $100 \mu \mathrm{W}$ to $10 \mathrm{~mW}$ or even higher [3]

This research is in part supported by Research Grant Council CERG HKUST 614506 and 620305.
[4]. Switch-mode power converters (switching converters) are often used due to its high efficiency. However, an offchip bulky inductor is needed. Research in recent years has reduced the total power consumption of a sensor node to less than $1 \mathrm{~mW}$, and fully integrated small size solution becomes increasingly realistic and desirable in some cases. In addition, [5] shows that low-level vibration with available power of less than $100 \mu \mathrm{W}$ and fundamental frequency of less than $200 \mathrm{~Hz}$ can be widely found in many situations. One challenge is to harvest energy efficiently from low-level vibration with low source voltage. Another challenge is to provide high power conversion efficiency over a wide range of source voltage without using switching converters. Furthermore, a fast power transfer rate is desirable such that the system could make the most use of short bursts of highenergy instants.

In this research, we propose an energy-adaptive MPPT power management unit for harvesting energy from very low level vibrations. Available power is measured by a simple "load perturbation" method that is basically a trial-and-error process. With this information the PMU could instruct the system to operate in different modes. A high-efficiency ac-dc doubler provides an adequate output voltage without resorting to additional step-up dc-dc converters for low vibration levels. Fully-integrated charge pumps with variable conversion ratios are used to replace switching converters. Fast energy accumulation and small input and output voltage ripples are achieved by time-interleaving techniques.

\section{SYSTEM OPERATION}

Fig. 1 shows the PMU of the sensor node with two types of load. (1) Baseband analog and digital circuits such as sensor front-end, A/D converters, computation logic and memory circuits consume about $10-20 \mu \mathrm{W}$ and should remain active if possible. (2) RF circuits consume about $1 \mathrm{~mW}$ and should be activated if enough energy is accumulated for transmission. Due to size limitation the piezoelectric device may only provide a maximum of $100 \mu \mathrm{W}$. Because the total power consumption exceeds the maximum power provided by the source, the transmitter has to work in a duty-cycled fashion. The energy for transmission is accumulated on storage capacitors $\mathrm{C}_{\mathrm{SRF} 1}$ and $\mathrm{C}_{\mathrm{SRF} 2}$. The $\mathrm{RF}$ blocks are supplied by 


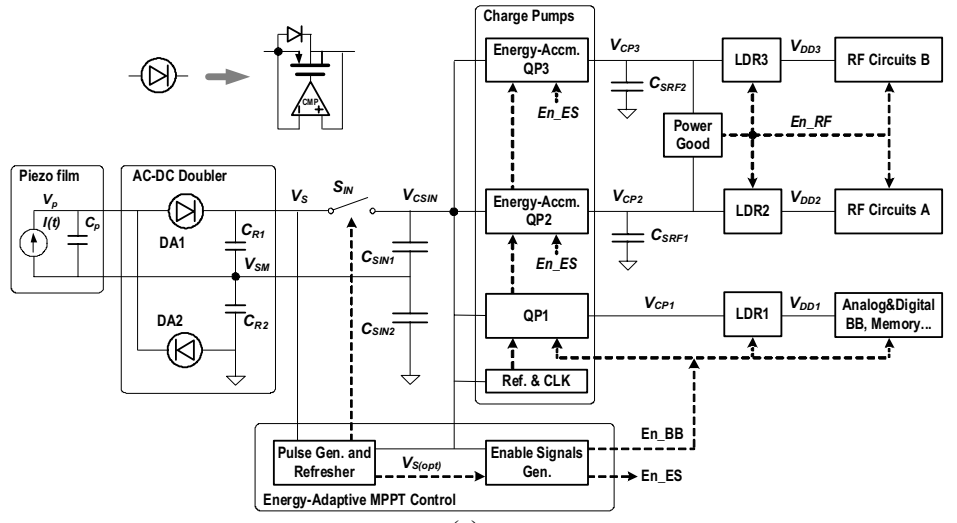

(a)

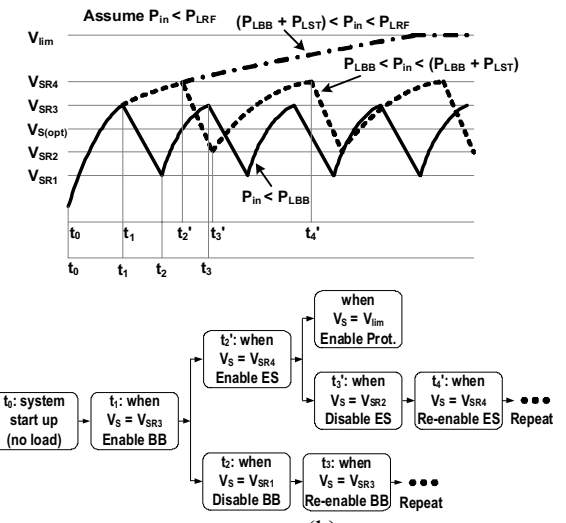

(b)

Fig. 1. System operation: (a) system diagram; and (b) voltage waveform of $V_{S}$ and mode transition diagram for different available power.

$\mathrm{V}_{\mathrm{DD} 2}$ and $\mathrm{V}_{\mathrm{DD} 3}$ such that noise-sensitive circuits and noisy circuits can be isolated.

The PMU starts with an ac-de rectifying doubler followed by three charge pumps. The first charge pump $\mathrm{QP}_{1}$ provides power for the baseband analog and digital circuits (BB). The charge pumps $\mathrm{QP}_{2}$ and $\mathrm{QP}_{3}$ charge up $\mathrm{C}_{\mathrm{SRF} 1}$ and $\mathrm{C}_{\mathrm{SRF} 2}$ instead of supplying current directly to RF circuits RF-A and RF-B. The outputs of all charge pumps are regulated by low dropout regulators (LDRs). The energy-adaptive MPPT control block generates the enable signal En $\mathrm{BB}$ for $\mathrm{QP}_{1}$, $\mathrm{LDR}_{1}$ and baseband circuits, and the enable signal En_ES for controlling $\mathrm{QP}_{2}$ and $\mathrm{QP}_{3}$ for energy storage. A Power-Good block senses the voltage on $\mathrm{C}_{\mathrm{SRF} 1}$ and $\mathrm{C}_{\mathrm{SRF} 2}$ to decide whether the stored energy is adequate for the RF circuits.

\section{A. Maximum Power Point}

The piezoelectric thin film is modeled by an sinusoidal current source $\mathrm{I}(\mathrm{t})=\mathrm{I}_{\mathrm{p}} \sin (2 \pi \mathrm{ft})$ in parallel with the internal capacitance $\mathrm{C}_{\mathrm{p}}$. The amplitude $\mathrm{I}_{\mathrm{p}}$ depends on the vibration magnitude and $f$ is the vibration frequency. Using transistors as active diodes, the forward drop $V_{d p}$ is close to zero [6], and the average rectifier output current $\mathrm{I}_{\text {inavg }}$ and the average harvested power $\mathrm{P}_{\text {inavg }}$ are

$$
\begin{array}{ll}
\mathrm{I}_{\text {inavg }} & =\mathrm{I}_{\mathrm{p}} / \pi-\mathrm{fC}_{\mathrm{p}}\left(\mathrm{V}_{\mathrm{S}}+2 \mathrm{~V}_{\mathrm{dp}}\right) \\
\mathrm{P}_{\text {inavg }} & =\left[\mathrm{I}_{\mathrm{p}} / \pi-\mathrm{fC}_{\mathrm{p}}\left(\mathrm{V}_{\mathrm{S}}+2 \mathrm{~V}_{\mathrm{dp}}\right)\right] \mathrm{V}_{\mathrm{S}}
\end{array}
$$

where $V_{S}$ is the output voltage of the rectifier. Maximum power is obtained when $\mathrm{V}_{\mathrm{S}}$ is

$$
\mathrm{V}_{\mathrm{S}(\mathrm{opt})} \quad=\mathrm{I}_{\mathrm{p}} / 2 \pi \mathrm{fC}_{\mathrm{p}}-\mathrm{V}_{\mathrm{dp}}
$$

From (2) and (3) the maximum power is

$$
\mathrm{P}_{\text {avg(opt })}=\mathrm{fC}_{\mathrm{p}}\left(\mathrm{I}_{\mathrm{p}} / 2 \pi \mathrm{fC}_{\mathrm{p}}-\mathrm{V}_{\mathrm{dp}}\right)^{2}
$$

To obtain the voltage $\mathrm{V}_{\mathrm{S}(\mathrm{opt})}$, we use the MPPT method of [2], which disconnect the load by opening $\mathrm{S}_{\mathrm{IN}}$ in Fig. 1 for a very short time and sense the open-circuit peak voltage of the piezoelectric source for control:

$$
\mathrm{V}_{\mathrm{p} \text { (open) }}=\mathrm{I}_{\mathrm{p}} / 2 \pi \mathrm{fC}_{\mathrm{p}}
$$

It is approximately equal to the optimum voltage $\mathrm{V}_{\mathrm{S}(\mathrm{opt})}$ when the voltage drop $V_{d p}$ is small.
TABLE I. OPERATING MODES

\begin{tabular}{c|c|c|c}
\hline \hline $\begin{array}{c}\text { Input power range } \\
\left.\text { (assuming } \mathrm{P}_{\mathrm{IN}}<\mathrm{P}_{\mathrm{LRF}}\right)\end{array}$ & $\begin{array}{c}\text { Baseband \& } \\
\mathrm{QP}_{1}, \mathrm{LDR}_{1} \\
\left(\mathrm{P}_{\mathrm{LBB}}\right)\end{array}$ & $\begin{array}{c}\text { Energy } \\
\text { Accum. by } \\
\mathrm{QP}_{2,3}\left(\mathrm{P}_{\mathrm{LES}}\right)\end{array}$ & $\begin{array}{c}\mathrm{RF} \text { circuits, } \mathrm{LDR}_{2,3} \\
\left(\mathrm{P}_{\mathrm{LRF}}\right)\end{array}$ \\
\hline $\mathrm{P}_{\mathrm{IN}}<\mathrm{P}_{\mathrm{LBB}}$ & $\begin{array}{c}\text { Duty-cycled } \\
\text { operation }\end{array}$ & Sleep & Sleep \\
\hline $\mathrm{P}_{\mathrm{LBB}}<\mathrm{P}_{\mathrm{IN}}<\mathrm{P}_{\mathrm{LBB}}+\mathrm{P}_{\mathrm{LES}}$ & $\begin{array}{c}\text { Continuous } \\
\text { operation }\end{array}$ & $\begin{array}{c}\text { Duty-cycled } \\
\text { Energy Accum. }\end{array}$ & $\begin{array}{c}\text { (low) Duty-cycled } \\
\text { operation }\end{array}$ \\
\hline $\mathrm{P}_{\mathrm{LBB}}+\mathrm{P}_{\mathrm{LES}}<\mathrm{P}_{\mathrm{IN}}<\mathrm{P}_{\mathrm{LRF}}$ & $\begin{array}{c}\text { Continuous } \\
\text { operation }\end{array}$ & $\begin{array}{c}\text { Continuous } \\
\text { Energy Accum. }\end{array}$ & $\begin{array}{c}\text { (high) Duty-cycled } \\
\text { operation }\end{array}$ \\
\hline \hline
\end{tabular}

\section{B. Energy-Adaptive MPPT}

The value of $\mathrm{V}_{\mathrm{S}(\mathrm{opt})}$ is not adequate to tell whether the available power becomes higher or lower. This can be seen from (3) and (4). When both the current $I_{p}$ and the vibration frequency $f$ are doubled, the optimum voltage $\mathrm{V}_{\mathrm{S}(\mathrm{opt})}$ will remain the same but the available power $\mathrm{P}_{\text {avg(opt }}$ is doubled. To adaptively operate individual part in different modes, a method to detect the absolute or relative amount of available power is then needed.

Here we propose a simple "load perturbation" technique. The system always tries to operate all the blocks continuously, starting from the most critical block, and then responds to the change of $V_{S}$. Here the load itself is used as the yardstick against which the amount of available power relative to the load is measured. Fig. 1(b) shows the voltage $\mathrm{V}_{\mathrm{S}}$ for different power levels and mode transition. As mentioned previously, the input power $\mathrm{P}_{\text {in }}$ is always less than the power dissipation of the RF part $\mathrm{P}_{\mathrm{RF}}$.

Assume initially all the loads are disabled and the capacitors $\mathrm{C}_{\mathrm{SIN} 1}$ and $\mathrm{C}_{\mathrm{SIN} 2}$ are charged from a very low level at $t_{0}$. Four reference voltages $\mathrm{V}_{\mathrm{SR} 1}, \mathrm{~V}_{\mathrm{SR} 2}, \mathrm{~V}_{\mathrm{SR} 3}$, and $\mathrm{V}_{\mathrm{SR} 4}$ are generated based on the detected optimum voltage $V_{S(o p t)}$. These voltage levels are closely centered around $V_{S(\text { opt) }}$ and track the variation of $\mathrm{V}_{\mathrm{S}(\mathrm{opt})}$. $\mathrm{V}_{\mathrm{S}}$ should be kept within $\mathrm{V}_{\mathrm{SR} 1}$ and $\mathrm{V}_{\mathrm{SR} 4}$ for (approximately) optimum power transfer. When $V_{S}$ reaches $V_{S R 3}$ at $t_{1}$, the analog and digital baseband (BB) will be activated. What will happen next depends on the available power levels:

(a) $P_{\text {in }}<P_{L B B}$ : If the input power $P_{\text {in }}$ is less than the baseband power $\mathrm{P}_{\mathrm{LBB}}, \mathrm{V}_{\mathrm{S}}$ will drop after $\mathrm{t}_{1}$. $\mathrm{BB}$ will be kept on until $\mathrm{V}_{\mathrm{SR} 1}$ is crossed at $\mathrm{t}_{2}$. Then $\mathrm{BB}$ will be 
disabled. Since $V_{S}$ is unloaded now it will rise again. At $t_{3}, V_{S}$ crosses $V_{S R 3}$ again and $B B$ is re-enabled. The process will repeat.

(b) $\mathrm{P}_{\text {in }}>\mathrm{P}_{\mathrm{LBB}}$ : If the input power $\mathrm{P}_{\text {in }}$ is larger than the baseband power $P_{L B B}, V_{S}$ will continue to increase after $t_{1}$. BB will be kept on. When $V_{S R 4}$ is crossed at $t_{2}{ }^{\prime}$, the energy storage (ES) process will be enabled. What will happen depends again on the available power levels:

(b1) $\mathrm{P}_{\mathrm{LBB}}<\mathrm{P}_{\text {in }}<\mathrm{P}_{\mathrm{LBB}}+\mathrm{P}_{\mathrm{LES}}$ : If $\mathrm{P}_{\text {in }}$ is smaller than the total power dissipation of $B B$ and $E S$, then $V_{S}$ will decrease after $t_{2}{ }^{\prime}$. BB and ES will be kept on until $V_{\mathrm{SR} 2}$ is crossed at $t_{3}{ }^{\prime}$. At this time, ES will be disabled but $\mathrm{BB}$ is still kept enabled. Because $P_{\text {in }}>P_{\text {LBB }}$, the $V_{S}$ will rise again. At $t_{4}{ }^{\prime} V_{S R 4}$ is crossed again, ES will be re-enabled and the above process will repeat.

(b2) $\mathrm{P}_{\mathrm{LBB}}+\mathrm{P}_{\mathrm{LES}}<\mathrm{P}_{\text {in }}<\mathrm{P}_{\mathrm{LRF}}$ : If $\mathrm{P}_{\text {in }}$ is greater than the total power of $B B$ and $E S$ but less than the RF part, $V_{S}$ will keep moving upwards after $\mathrm{t}_{2}{ }^{\prime}$. Finally, it will reach the limit value $\mathrm{V}_{\text {lim, }}$ which is very large and any voltage above it should be prevented. Whether or not the RF part will be activated does not depend on $V_{S}$ reaching $\mathrm{V}_{\text {lim, }}$, but on whether the amount of stored energy is adequate, which may happen before or after the instant when $\mathrm{V}_{\mathrm{S}}$ reaches $\mathrm{V}_{\text {lim }}$.

It can be seen that by perturbing the load and watching for the level crossing events, we can obtain the information of the available power level relative to the load power level. At the same time, $V_{\mathrm{S}}$ fluctuates around the optimum point, providing maximum power transfer. Table I shows the operation modes for different input power.

\section{Circuit Designs And Considerations}

\section{A. AC-DC Doubler}

Compared to full-wave rectifier with only one large capacitor, the two half-wave rectifiers in cascade needs two large capacitors $\mathrm{C}_{\mathrm{SIN} 1}$ and $\mathrm{C}_{\mathrm{SIN} 2}$, but the output dc voltage is doubled. The two capacitors are $10 \mu \mathrm{F}$ and can be surfacemount capacitors which are very small. For low vibration levels, the doubler output $\mathrm{V}_{\mathrm{S}}$ can be high enough to be used directly by the load, without using an additional dc-dc converter. The two diodes $\mathrm{DA}_{1}$ and $\mathrm{DA}_{2}$ are active diodes for higher efficiency [6]. The storage capacitors $\mathrm{C}_{\mathrm{SIN} 1}$ and $\mathrm{C}_{\mathrm{SIN} 2}$ should not be too large or too small. The lower limit is set by the minimum stored energy in a charge-discharge cycle to complete an atomic operation, and the voltage ripple has to be small enough to avoid disturbing the decision making of the comparators in the MPPT block. A large capacitor stores more energy and has less ripple voltage, but increases the system start-up time. A long start-up time will cause short bursts of energy to be missed, which is undesirable.

\section{B. Energy-Adaptive MPPT Control Block}

As shown in Fig. 2, the energy-adaptive MPPT control block consists of a Tracking Pulse Generator, a Refresher, and an Enable Signals Generation circuits. The pulse generator is used to recover the clock from the input and

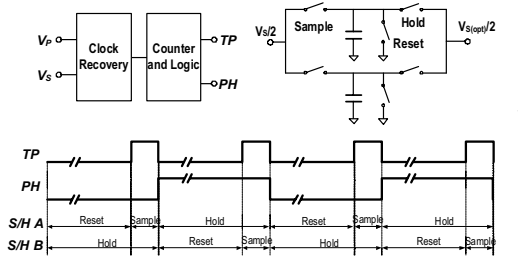

(a)

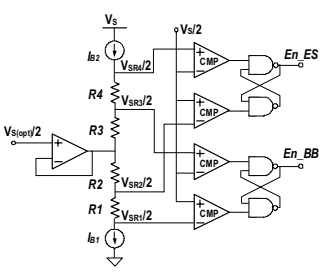

(b)
Fig. 2. Energy-adaptive MPPT circuits: (a) tracking pulse generator and refresher and its timing; and (b) enable signals generation.

generates a pulse TP that is two cycles long for every 128 cycles. During these two cycles, the switch $\mathrm{S}_{\mathrm{IN}}$ is open, putting the piezoelectric film into the open-circuit state. The two capacitors $C_{F 1}$ and $C_{F 2}$ are small enough to allow $V_{S}$ to settle to $\mathrm{V}_{\mathrm{S}(\mathrm{opt})}$ within two cycles. The refresher circuit is to sample the present value of $\mathrm{V}_{\mathrm{S}(\mathrm{opt})}$ and discard the last one [2]. The last value has to be held for normal operation during the sampling period of the present one, so the refresher circuit consists of two time-multiplexed sample-and-hold $(\mathrm{S} / \mathrm{H})$ circuits. In practice, $\mathrm{V}_{\mathrm{S}(\mathrm{opt})} / 2$ is generated instead of $\mathrm{V}_{\mathrm{S}(\mathrm{opt})}$, because the supply voltage $\mathrm{V}_{\mathrm{S}}$ is close to $\mathrm{V}_{\mathrm{S}(\mathrm{opt}) \text {. }}$.

Four reference voltages $\mathrm{V}_{\mathrm{SR} 1} / 2, \mathrm{~V}_{\mathrm{SR} 2} / 2, \mathrm{~V}_{\mathrm{SR} 3} / 2$, and $\mathrm{V}_{\mathrm{SR} 4} / 2$ are generated by the circuit shown in Fig. 2(b). Four comparators each with a current consumption less than $100 \mathrm{nA}$ are used to compare the reference voltages with $\mathrm{V}_{\mathrm{S}} / 2$. The outputs of the comparators are used to set the operating mode of the PMU. The comparators should have large input devices to reduce the standard deviation of the random offset voltage to a very small fraction of the difference between two neighboring reference voltages.

\section{Charge Pumps}

The output voltage of the ac-dc doubler is in the range of $1.4 \mathrm{~V}$ to $5 \mathrm{~V}$ and the targeted supply voltages for baseband $\left(\mathrm{V}_{\mathrm{DD} 1}\right)$, RF Circuit $\mathrm{A}\left(\mathrm{V}_{\mathrm{DD} 2}\right)$ and $\mathrm{RF}$ Circuit $\mathrm{B}\left(\mathrm{V}_{\mathrm{DD} 3}\right)$ are $0.85 \mathrm{~V}, 1.55 \mathrm{~V}$ and $2.45 \mathrm{~V}$ respectively. To make the efficiency comparable to a switching converter, the charge pump has to be highly reconfigurable according to the input voltage $\mathrm{V}_{\mathrm{CSIN}}$ [7]. The conversion ratios (M) are dynamically configured as shown in Table II.

Fig. 3 shows the schematic of the charge pump $\mathrm{QP}_{2}$ for RF-A. The control logics for the corresponding power switches are shown in Fig. 4. For example, the switch $\mathrm{S}_{7}$ has a control logic of $r_{1} \mid \phi_{1}\left(r_{2}\right)$, meaning that $S_{7}$ will be turned on when $M$ is $1 X\left(r_{1}=" 1 "\right)$ or during $\phi_{1}$ when $M$ is $2 X\left(r_{2}=" 1 "\right)$. It will be kept off for other cases. Similar schematics and control logics are developed for the other charge pumps.

As mentioned before, $\mathrm{QP}_{2}$ and $\mathrm{QP}_{3}$ are used for accumulating power for circuits RF-A and RF-B. It should be noted that the charging priority of $\mathrm{QP}_{3}$ is higher or $\mathrm{QP}_{2}$ has to "wait" until $\mathrm{QP}_{3}$ has charged $\mathrm{C}_{\mathrm{SRF} 2}$ to above $2.6 \mathrm{~V}$. This high voltage is used to drive some switches in $\mathrm{QP}_{2}$ such that their sizes could be much smaller. To accelerate the power conversion process and reduce the I/O current/voltage ripples, interleaving technique is employed for $\mathrm{QP}_{3}$, as shown in Fig. 5. The schematics of $\mathrm{QP}_{31} \sim \mathrm{QP}_{34}$ are the same and their driving signals $\phi_{1} \sim \phi_{4}$ are from the ring oscillator. 
Table II Conversion Ratio Management

\begin{tabular}{|c|c|c|c|c|c|}
\hline Blocks & $\mathrm{V}_{\mathrm{CSIN}}$ & $\mathrm{QP}_{\mathrm{i}} \mathrm{M}=$ & $\mathrm{V}_{\mathrm{CPi}}$ & $\mathrm{V}_{\mathrm{DDi}}$ & $\mathrm{I}_{\max }$ \\
\hline \multirow[t]{4}{*}{ RF-B (i=3) } & $4.2 \mathrm{~V} \sim 3.6 \mathrm{~V}$ & 1 & \multirow[t]{4}{*}{$>2.6 \mathrm{~V}$} & \multirow[t]{4}{*}{$2.45 \mathrm{~V}$} & \multirow[t]{4}{*}{$10 \mathrm{~mA}$} \\
\hline & $2.6 \mathrm{~V} \sim 1.8 \mathrm{~V}$ & $3 / 2$ & & & \\
\hline & $1.8 \mathrm{~V} \sim 1.4 \mathrm{~V}$ & 2 & & & \\
\hline & $1.4 \mathrm{~V} \sim 0.9 \mathrm{~V}$ & 3 & & & \\
\hline \multirow[t]{7}{*}{ RF-A (i=2) } & $4.2 \mathrm{~V} \sim 3.6 \mathrm{~V}$ & $1 / 2$ & \multirow[t]{7}{*}{$>1.7 \mathrm{~V}$} & \multirow[t]{7}{*}{$1.55 \mathrm{~V}$} & \multirow[t]{7}{*}{$1 \mathrm{~mA}$} \\
\hline & $3.6 \mathrm{~V} \sim 2.4 \mathrm{~V}$ & $3 / 4$ & & & \\
\hline & $2.4 \mathrm{~V} \sim 1.8 \mathrm{~V}$ & 1 & & & \\
\hline & $1.8 \mathrm{~V} \sim 1.44 \mathrm{~V}$ & $5 / 4$ & & & \\
\hline & $1.44 \mathrm{~V} \sim 1.2 \mathrm{~V}$ & $3 / 2$ & & & \\
\hline & $1.2 \mathrm{~V} \sim 1 \mathrm{~V}$ & $7 / 4$ & & & \\
\hline & $1 \mathrm{~V} \sim 0.9 \mathrm{~V}$ & 2 & & & \\
\hline \multirow[t]{5}{*}{$\mathrm{BB}(\mathrm{i}=1)$} & $4.2 \mathrm{~V} \sim 3.6 \mathrm{~V}$ & $1 / 4$ & \multirow[t]{5}{*}{$>0.9 \mathrm{~V}$} & \multirow[t]{5}{*}{$0.85 \mathrm{~V}$} & \multirow[t]{5}{*}{$20 \mu \mathrm{A}$} \\
\hline & $3.6 \mathrm{~V} \sim 2.7 \mathrm{~V}$ & $1 / 3$ & & & \\
\hline & $2.7 \mathrm{~V} \sim 1.8 \mathrm{~V}$ & $1 / 2$ & & & \\
\hline & $1.8 \mathrm{~V} \sim 1.2 \mathrm{~V}$ & $3 / 4$ & & & \\
\hline & $1.2 \mathrm{~V} \sim 0.9 \mathrm{~V}$ & 1 & & & \\
\hline
\end{tabular}

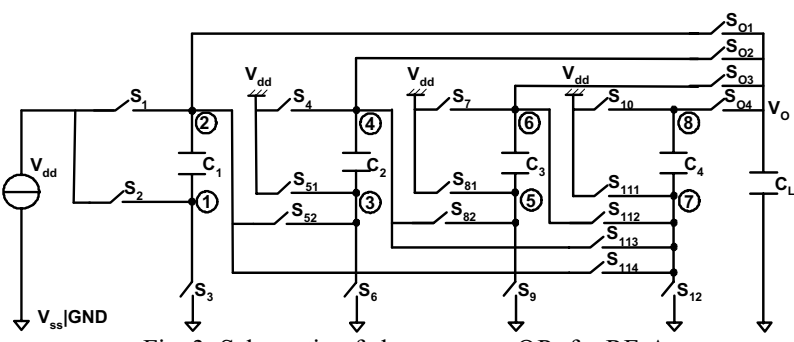

Fig. 3. Schematic of charge pump $\mathrm{QP}_{2}$ for RF-A.

\begin{tabular}{|c|c|c|c|c|c|}
\hline $\mathrm{s}_{1}$ & $r_{1} \mid \phi_{1}\left(r_{2}\right)$ & $S_{7}$ & $r_{1} \mid \phi_{1}\left(r_{2}\right)$ & $S_{113}$ & $\phi_{1}\left(\mathbf{r}_{34} \mid \mathbf{r}_{74}\right)$ \\
\hline$s_{2}$ & $\phi_{2}\left(\mathbf{r}_{54}\left|\mathbf{r}_{32}\right| \mathbf{r}_{74} \mid \mathbf{r}_{2}\right)$ & $\mathbf{S}_{81}$ & $\phi_{2}\left(\mathbf{r}_{54}\left|\mathbf{r}_{32}\right| \mathbf{r}_{2}\right)$ & $S_{114}$ & $\phi_{1}\left(\mathbf{r}_{34} \mid \mathbf{r}_{74}\right)$ \\
\hline $\mathrm{S}_{3}$ & $\mathbf{r}_{12}\left|\mathbf{r}_{34}\right| \mathbf{r}_{1} \mid \phi_{1}$ & $S_{82}$ & $\phi_{1}\left(\mathbf{r}_{54}\right) \mid \phi_{2}\left(\mathbf{r}_{34} \mid \mathbf{r}_{74}\right)$ & $S_{12}$ & $\mathbf{r}_{1}\left|\phi_{1}\left(\mathbf{r}_{2}\right)\right| \phi_{2}\left(\mathbf{r}_{12} \mid \mathbf{r}_{34}\right)$ \\
\hline $\mathrm{S}_{4}$ & $\mathbf{r}_{1} \mid \phi_{1}\left(\mathbf{r}_{12}\left|\mathbf{r}_{32}\right| \mathbf{r}_{2}\right)$ & $S_{9}$ & $\mathbf{r}_{12}\left|r_{1}\right| \phi_{1}\left(\overline{r_{54}}\right)$ & $s_{01}$ & $\mathbf{r}_{1} \mid \phi_{2}\left(\mathbf{r}_{12}\left|\mathbf{r}_{54}\right| \mathbf{r}_{32} \mid \mathbf{r}_{2}\right)$ \\
\hline$S_{51}$ & $\phi_{2}\left(\mathbf{r}_{54}\left|\mathbf{r}_{32}\right| \mathbf{r}_{2}\right)$ & $\mathrm{S}_{10}$ & $r_{1} \mid \phi_{1}$ & $\mathrm{~s}_{\mathrm{O} 2}$ & $\mathbf{r}_{1} \mid \phi_{2}\left(\mathbf{r}_{12}\left|\mathbf{r}_{54}\right| \mathbf{r}_{32} \mid \mathbf{r}_{2}\right)$ \\
\hline$S_{52}$ & $\phi_{1}\left(\mathbf{r}_{12}\left|\mathbf{r}_{54}\right| \mathbf{r}_{32}\right)\left|\phi_{2}\left(\mathbf{r}_{34} \mid \mathbf{r}_{74}\right)\right|$ & $S_{111}$ & $\phi_{2}\left(\mathbf{r}_{54}\left|\mathbf{r}_{32}\right| \mathbf{r}_{74} \mid \mathbf{r}_{2}\right)$ & $\mathrm{s}_{\mathrm{O} 3}$ & $r_{1} \mid \phi_{2}$ \\
\hline$S_{6}$ & $\mathbf{r}_{1}\left|\phi_{1}\left(\mathbf{r}_{34}\left|\mathbf{r}_{74}\right| \mathbf{r}_{2}\right)\right| \phi_{2}\left(\mathbf{r}_{12}\right)$ & $S_{112}$ & $\phi_{1}\left(\overline{r_{2}}\right)$ & $s_{04}$ & $\mathrm{r}_{1} \mid \phi_{2}$ \\
\hline
\end{tabular}

Fig. 4. Control logic of power switches in Fig. 3.
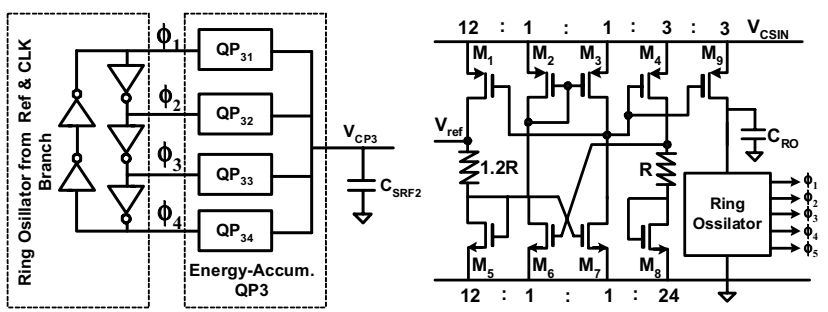

Fig. 5. Interleaved $\mathrm{QP}_{3}$.

Fig. 6. Reference and clock generator.

\section{Ref \& CLK Branch for Start-Up}

The reference voltage used to determine the conversion ratios of charge pumps does not need to be very accurate, and can be implemented by using MOS-only topology shown in Fig. 6. Diode $M_{5}$ and $M_{8}$ operate in sub-threshold region and $\mathrm{M}_{2}, \mathrm{M}_{3}, \mathrm{M}_{6}$, and $\mathrm{M}_{7}$ act as a clamping opamp. $\mathrm{V}_{\text {ref }}$ varies by $6 \mathrm{mV}$ across the whole operation range $\left(\mathrm{V}_{\mathrm{CSIN}}: 0.9 \mathrm{~V} \sim 4.2 \mathrm{~V}\right.$; Temperature: $-20^{\circ} \sim 100^{\circ}$ ). A 5-stage ring oscillator could generate all driving signals with a frequency that ranges from $1.6 \mathrm{MHz}$ to $2.5 \mathrm{MHz}$. The total current consumption for this block is around $400 \mathrm{nA}$ with $\mathrm{V}_{\text {ref }}=758 \mathrm{mV}$ and $\mathrm{f}_{\text {osc }}=2 \mathrm{MHz}$ at $\mathrm{V}_{\mathrm{CSIN}}=2 \mathrm{~V}$ and $\mathrm{T}=25^{\circ}$. The start-up circuit is not shown.

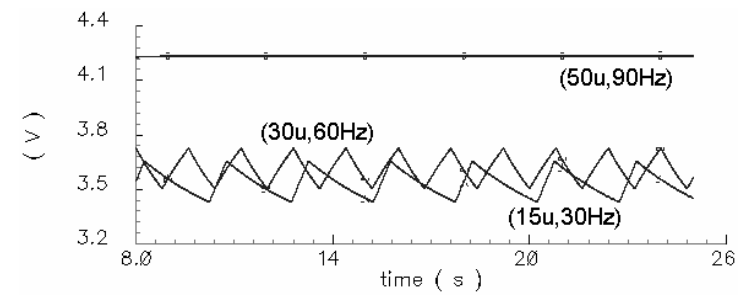

Fig. 7. Simulated voltage waveforms of $\mathrm{V}_{\mathrm{SIN}}$ for different power levels.

\section{Simulation Results}

Fig. 7 shows the simulated voltage waveform of $\mathrm{V}_{\text {SIN }}$ for three cases: (1) $\mathrm{I}_{\mathrm{p}}=15 \mu \mathrm{A}, f=30 \mathrm{~Hz}$ and $\mathrm{P}_{\text {avg(opt) }}=8.54 \mu \mathrm{W}$. (2) $\mathrm{I}_{\mathrm{p}}=30 \mu \mathrm{A}, f=60 \mathrm{~Hz}$ and $\mathrm{P}_{\text {avg(opt) }}=17.08 \mu \mathrm{W}$. (3) $\mathrm{I}_{\mathrm{p}}=50 \mu \mathrm{A}$, $f=90 \mathrm{~Hz}$ and $\mathrm{P}_{\text {avg(opt })}=31.63 \mu \mathrm{W}$. Both the load power $\mathrm{P}_{\mathrm{LBB}}$ and $\mathrm{P}_{\mathrm{LES}}$ are equal to $10 \mu \mathrm{W}$. The first two cases have the same $\mathrm{V}_{\mathrm{s}(\mathrm{opt})}$ of $3.578 \mathrm{~V}$. It can be seen that, for case $1, \mathrm{~V}_{\mathrm{SIN}}$ fluctuates between $3.652 \mathrm{~V}$ and $3.431 \mathrm{~V}$, with an average of $3.541 \mathrm{~V}$. For case $2, \mathrm{~V}_{\mathrm{SIN}}$ is between $3.725 \mathrm{~V}$ and $3.507 \mathrm{~V}$, and the average is $3.616 \mathrm{~V}$. For both cases, the average voltage is very close to the optimum value. The input power for case 3 is larger than the sum of $\mathrm{P}_{\mathrm{LBB}}$ and $\mathrm{P}_{\mathrm{LES}}$ so $\mathrm{V}_{\mathrm{SIN}}$ stays at $4.234 \mathrm{~V}$, which is above the optimum value of $3.976 \mathrm{~V}$.

\section{Conclusions}

In this paper, an energy-adaptive MPPT power management unit for harvesting energy from very low level vibration is proposed. By a simple control method, it sets the system in different operation modes depending on the available power level. Fully-integrated time-interleaved charge pumps with variable conversion ratios are used to replace the switching converter, eliminating the need of an external bulky inductor. A very low power voltage reference is used to generate the reference voltages for start-up. The functionality of the MPPT scheme is verified by simulations.

\section{REFERENCES}

[1] G. K. Ottman, A. C. Bhatt, H. Hofmann and G. A. Lesieutre, "Adaptive piezoelectric energy harvesting circuit for wireless remote power supply," IEEE Trans. Power Electronics, pp. 669-676, Sep. 2002.

[2] C. Lu, C. Y. Tsui, and W. H. Ki, "Vibration energy scavenging and management for ultra low power applications," IEEE Int'l Symp. on Low Power Elec. Devices, pp. 316-321, Aug. 2007.

[3] N. Shenck and J. A. Paradiso, "Energy scavenging with shoe-mounted piezoelectrics," IEEE Micro, pp.30-42, May-Jun. 2001.

[4] G. K. Ottman, H. F. Hofmann, and G. A. Lesieutre, "Optimized piezoelectric energy harvesting circuit using step-down converter in discontinuous conduction mode," IEEE Trans. Power Electronics, pp.696-703, Mar. 2003.

[5] S. Roundy, P. K. Wright, J. Rabaey, "A study of low level vibrations as a power source for wireless sensor nodes," Computer Communications, pp.1131-1144, 2003.

[6] Y. H. Lam, W. H. Ki and C. Y. Tsui, "Integrated low-loss CMOS active rectifier for wirelessly powered devices," IEEE Trans. on Ckts. \& Sys., Part II, pp.1378-1382, Dec. 2006.

[7] F. Su and W. H. Ki, "Design strategy for step-up charge pumps with variable integer conversion ratios," IEEE Trans. on Ckts. \& Sys., Part II, pp.417-421, May 2007. 